\title{
Clinical, histological, and genetic characterization of PYROXD1-related myopathy
}

\author{
Xavière Lornage ${ }^{1,2,3,4}$, Vanessa Schartner ${ }^{1,2,3,4}$, Inès Balbueno ${ }^{1,2,3,4}$, Valérie Biancalana ${ }^{1,2,3,4,5}$, Tracey Willis ${ }^{6}$, \\ Andoni Echaniz-Laguna ${ }^{7,8,9}$, Sophie Scheidecker ${ }^{10}$, Ros Quinlivan ${ }^{11}$, Michel Fardeau ${ }^{12,13,14}$, Edoardo Malfatti ${ }^{15}$,

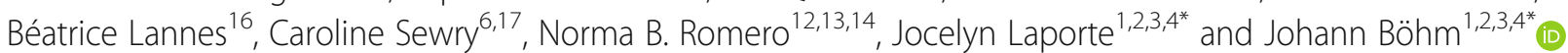

\begin{abstract}
Recessive mutations in PYROXD1, encoding an oxidoreductase, were recently reported in families with congenital myopathy or limb-girdle muscular dystrophy. Here we describe three novel PYROXD1 families at the clinical, histological, and genetic level. Histological analyses on muscle biopsies from all families revealed fiber size variability, endomysial fibrosis, and muscle fibers with multiple internal nuclei and cores. Further characterization of the structural muscle defects uncovered aggregations of myofibrillar proteins, and provided evidence for enhanced oxidative stress. Sequencing identified homozygous or compound heterozygous PYROXD1 mutations including the first deep intronic mutation reinforcing a cryptic donor splice site and resulting in mRNA instability through exonisation of an intronic segment. Overall, this work expands the PYROXD1 mutation spectrum, defines and specifies the histopathological hallmarks of the disorder, and indicates that oxidative stress contributes to the pathomechanism. Comparison of all new and published cases uncovered a genotype/phenotype correlation with a more severe and early-onset phenotypic presentation of patients harboring splice mutations resulting in reduced PYROXD1 protein levels compared with patients carrying missense mutations.
\end{abstract}

Keywords: PYROXD1, Oxidoreductase, Congenital myopathy, LGMD, Myofibrillar inclusions

\section{Introduction}

Myopathies are clinically and genetically heterogeneous and can be sub-classified based on the clinical presentation of the patients and notably on the presence of specific histological anomalies on muscle biopsies [5, 8]. Recently, PYROXD1 mutations were described in patients with slowly progressive congenital myopathy, and analysis of the muscle biopsies revealed multiple internal nuclei and cores, as well as myofibrillar inclusions [6]. Additional PYROXD1 cases were reported with childhood or adult-onset limbgirdle muscular dystrophy (LGMD) [9, 10]. PYROXD1 (pyridine nucleotide-disulfide oxidoreductase domaincontaining protein 1) is expressed in a multitude of tissues,

\footnotetext{
* Correspondence: jocelyn@igbmc.fr; johann@igbmc.fr

Xavière Lornage and Vanessa Schartner are co-first authors and contributed equally to this work. Jocelyn Laporte and Johann Böhm are co-last authors and contributed equally to this work.

${ }^{1}$ Institut de Génétique et de Biologie Moléculaire et Cellulaire (IGBMC), 1 rue Laurent Fries, 67404 Illkirch, France

Full list of author information is available at the end of the article
}

has a nuclear and cytosolic localization in skeletal muscle, and acts as an oxidoreductase potentially implicated in energy metabolism [6, 9]. Pyroxd1 downregulation in murine $\mathrm{C} 2 \mathrm{C} 12$ myoblasts impaired cellular proliferation, migration, and differentiation, and knockdown of the drosophila orthologue CG10721 is lethal, demonstrating that PYROXD1 is essential for normal development [9].

In total, nine families with recessive PYROXD1 mutations have been reported to date $[6,9,10]$. The identified mutations were evenly distributed over the gene and encompassed essential splice site mutations of in-frame exons, a 4-nucleotide insertion in the penultimate exon, and missense mutations affecting highly conserved amino acids. The most common p.(Asn155Ser) mutation was found in five families at the homozygous state and in three further families at the heterozygous state in combination with another mutation. Here we report additional patients from three unrelated families harboring three known and one new PYROXD1 mutation. We 
describe for the first time a deep intronic mutation and thereby highlight RNA sequencing as a method to diagnose PYROXD1 cases. Investigations on the patient biopsies revealed fibers with foetal myosin and increased oxidative stress markers. We also compared all published and new PYROXD1 patients and provide an overview on the clinical, histological and genetic spectrum of PYROXD1-related myopathy and draw a genotype/ phenotype correlation.

\section{Materials and methods}

\section{Patients}

Sample collection was performed with written informed consent from the patients according to the declaration of Helsinki and its later amendments. DNA storage and usage was IRB-approved (DC-2012-1693).

\section{Morphological analyses}

Patient P1 from Family 1 underwent open muscle biopsy at the age of 6, P2 (Family 2) underwent two open muscle biopsies at 29 and 66 years of age, and P3 (Family 3) underwent open muscle biopsy at the age of 9 . For histological and histochemical analyses, transverse $10 \mu \mathrm{m}$ cryostat muscle sections were stained with Haematoxylin \& Eosin (H\&E), Nicotinamide adenosine dinucleotide-tetrazolium reductase (NADH-TR), modified Gomori Trichome (mGT), and cytochrome c oxidase (COX). For electron microscopy, muscle sections were fixed, post-fixed, and dehydrated according to standard procedures, and embedded in epon resin. For immunohistochemistry, following primary and secondary antibodies were used: mouse anti-desmin (D33, Abcam, Cambridge, UK), mouse anti-myotilin (Novocastra, Newcastle upon Tyne, UK), mouse anti-alpha B crystallin (1B6.1-3G4, Abcam), mouse anti-p62 (D-3, Santa Cruz Biotechnology, Dallas, USA, mouse anti-foetal myosin (Novocastra), and appropriate secondary antibodies (Alexa Fluor, Invitrogen, Carlsbad, CA, USA).

\section{Molecular diagnosis}

P1 (Family 1) was sequenced for a targeted panel of 210 neuromuscular disorders genes (MYOdiagHTS) on a NextSeq550 (Illumina), P2 (Family 2) was exomesequenced with the SureSelect Human all Exon $50 \mathrm{Mb}$ capture library v5 (Agilent, Santa Clara, USA) followed by paired-end sequencing on an Illumina HiSeq2500 (Illumina, San Diego, USA), and P3 (Family 3) was directly Sanger-sequenced for all coding exons and the adjacent splice-relevant regions of PYROXD1. Confirmation of variants and segregation was performed by Sanger sequencing for all families. The mutations were numbered according to GenBank NM_024854.4 and NP_079130.2 with +1 corresponding to the A of the ATG translation initiation codon.

\section{RNA analyses}

Skeletal muscle RNA from P3 (Family 3) and an agematched control were extracted from frozen muscle using the Precellys 24 homogenizer (Bertin Technologies, Montigny-le-Bretonneux, France). Relative expression of PYROXD1 was measured with the SYBR Green PCR Master Mix (Qiagen, Hilden, Germany) on a LightCycler 480 Real-Time PCR System (Roche, Basel, Switzerland) using human PYROXD1- and HPRT1-specific primer sets. For cDNA analysis, the RNA was reverse transcribed using the SuperScript ${ }^{\oplus}$ III kit (Invitrogen).

\section{Western blot}

Total muscle lysates were prepared in a buffer containing $50 \mathrm{mM}$ Tris, $100 \mathrm{mM} \mathrm{NaCl}, 1 \mathrm{mM}$ EGTA, 0.5\% NP-40, 0.5\% Triton-X100, 0.1\% SDS, $1 \mathrm{mM}$ DTT, $1 \mathrm{mM}$ PMSF, and a mix of protease inhibitor (Complete EDTA-free, Roche, Basel, Switzerland), and $50 \mu \mathrm{g}$ of protein extracts were loaded on a $10 \%$ SDS-Page gel. The following primary and secondary antibodies were used: sc-133,245 mouse antiGlutathione Reductase (Santa Cruz Biotechnology), rabbit anti-HSP70 (4872S, Cell Signaling Technology, Danvers, USA) mouse anti-GAPDH (MAB374, Millipore, Burlington, USA), and horseradish peroxidase (Jackson immunoresearch Europe, Cambridgeshire, UK). Membranes were revealed with the Supersignal west pico kit (ThermoFisher Scientific), and immunoblots were visualized on an Amersham Imager 600 (GE Healthcare Life Sciences, Chicago, USA). Quantifications of glutathione reductase and HSP70 reflect a single experiment.

\section{Results}

\section{Clinical reports}

The patients described in this study belong to three unrelated families and presented with an early-onset and progressive muscle disorder. The clinical and histological features are summarized in Table 1 and compared with all previously reported PYROXD1 families.

P1 and P3 were born to non-consanguineous parents, while the parents of P2 were first-degree cousins. P1 manifested neonatal hypotonia and delayed motor milestones with progressive axial muscle weakness. The patient is wheelchair-bound since the age of 12 years, and respiratory insufficiency requires non-invasive ventilation (NIV) and oxygen therapy since the age of 14 years. Additional clinical features included scoliosis and joint hypermobility. His younger brother was reported with a similar course of disease and perished at the age of 16 years from respiratory distress. Patient 2 had a childhood-disease onset with walking and running difficulties resulting from axial and proximal muscle weakness predominantly affecting the lower limbs. The patient was ambulant at the last clinical examination at the age of 66, and presented with a reduced vital capacity (VC) of $68 \%$. P3 had a similar disease course as P1 with 
Table 1 Clinical, genetic, and histological features of patients with PYROXD1 mutations. All families have been numbered according to the mutation position. Homozygous mutations are highlighted in bold

\begin{tabular}{|c|c|c|c|c|c|c|c|c|c|c|}
\hline Family & Patient & Mutation & Onset & $\begin{array}{l}\text { Muscle } \\
\text { weakness }\end{array}$ & $\begin{array}{l}\text { Muscle } \\
\text { histology }\end{array}$ & $\begin{array}{l}\text { Nasal } \\
\text { speech }\end{array}$ & Scoliosis & Respiration & Other features & Reference \\
\hline 1 & P1 & $\begin{array}{l}\text { c. } 285+1 G>A \\
\text { c. } 464 A>G \\
\text { p.(Asn155Ser) }\end{array}$ & Neonatal & $\begin{array}{l}\text { Axial, wheel- } \\
\text { chair-bound } \\
\text { since age } 12\end{array}$ & $\begin{array}{l}\text { Internal nuclei, } \\
\text { cores, fiber size } \\
\text { variability, } \\
\text { fibrosis }\end{array}$ & No & Yes & $\begin{array}{l}\text { NIV and } \\
\text { oxygen } \\
\text { therapy } \\
\text { since age } \\
14\end{array}$ & Joint hypermobility & $\begin{array}{l}\text { This } \\
\text { study }\end{array}$ \\
\hline \multirow[t]{2}{*}{2} & C.II.1 & $\begin{array}{l}\text { c. } 414+1 \mathrm{G}>\mathrm{A} \\
\text { c. } 464 \mathrm{~A}>\mathrm{G} \\
\text { p.(Asn155Ser) }\end{array}$ & Neonatal & $\begin{array}{l}\text { Axial, upper } \\
\text { and lower } \\
\text { limbs, facial } \\
\text { weakness }\end{array}$ & NA & Yes & Yes & Normal & $\begin{array}{l}\text { Joint hypermobility, } \\
\text { contractures, rigid } \\
\text { spine, high-arched } \\
\text { palate }\end{array}$ & $\begin{array}{l}\text { O'Grady } \\
\text { et al., } \\
2016 \text { [6] }\end{array}$ \\
\hline & C.II.2 & & Childhood & $\begin{array}{l}\text { Axial, upper } \\
\text { and lower } \\
\text { limbs, facial } \\
\text { weakness }\end{array}$ & $\begin{array}{l}\text { Internal nuclei, } \\
\text { cores, } \\
\text { myofibrillar } \\
\text { inclusions, } \\
\text { sarcomeric } \\
\text { disorganization }\end{array}$ & Yes & No & Normal & $\begin{array}{l}\text { Joint hypermobility, } \\
\text { high-arched palate }\end{array}$ & \\
\hline 3 & P2 & $\begin{array}{l}\text { c. } 464 A>G \\
\text { p. }(\text { Asn 155Ser })\end{array}$ & Childhood & $\begin{array}{l}\text { Axial, upper } \\
\text { and lower limbs }\end{array}$ & $\begin{array}{l}\text { Internal nuclei, } \\
\text { cores, } \\
\text { myofibrillar } \\
\text { inclusions }\end{array}$ & & No & VC 68\% & - & $\begin{array}{l}\text { This } \\
\text { study }\end{array}$ \\
\hline \multirow[t]{2}{*}{4} & B.II.2 & $\begin{array}{l}\text { c. } 464 A>G \\
\text { p. }(\text { Asn155Ser })\end{array}$ & Childhood & $\begin{array}{l}\text { Proximal and } \\
\text { axial, upper and } \\
\text { lower limbs, } \\
\text { facial weakness }\end{array}$ & NA & Yes & No & Normal & - & $\begin{array}{l}\text { O'Grady } \\
\text { et al., } \\
2016 \text { [6] }\end{array}$ \\
\hline & B.II.3 & & Childhood & $\begin{array}{l}\text { Proximal and } \\
\text { axial, upper and } \\
\text { lower limbs, } \\
\text { facial weakness }\end{array}$ & $\begin{array}{l}\text { Internal nuclei, } \\
\text { cores, } \\
\text { myofibrillar } \\
\text { inclusions, } \\
\text { sarcomeric } \\
\text { disorganization, } \\
\text { rods }\end{array}$ & Yes & No & Abnormal & Ptosis, retrognathia & \\
\hline \multirow[t]{2}{*}{5} & D.II.1 & $\begin{array}{l}\text { c. } 464 A>G \\
\text { p. }(\text { Asn 155Ser })\end{array}$ & Childhood & $\begin{array}{l}\text { Proximal and } \\
\text { axial, upper and } \\
\text { lower limbs, } \\
\text { facial weakness }\end{array}$ & NA & Yes & No & Normal & $\begin{array}{l}\text { Ptosis, high-arched } \\
\text { palate }\end{array}$ & $\begin{array}{l}\text { O'Grady } \\
\text { et al., } \\
2016 \text { [6] }\end{array}$ \\
\hline & D.II.3 & & Childhood & $\begin{array}{l}\text { Proximal and } \\
\text { axial, upper and } \\
\text { lower limbs, } \\
\text { facial weakness }\end{array}$ & $\begin{array}{l}\text { Internal nuclei, } \\
\text { cores }\end{array}$ & Yes & No & Normal & $\begin{array}{l}\text { Ptosis, high-arched } \\
\text { palate }\end{array}$ & \\
\hline 6 & 1 & $\begin{array}{l}\text { c. } 464 A>G \\
\text { p. }(\text { Asn 155Ser })\end{array}$ & Childhood & $\begin{array}{l}\text { Proximal, lower } \\
\text { limbs, } \\
\text { wheelchair- } \\
\text { bound since } \\
\text { age } 37\end{array}$ & NA & No & No & Normal & - & $\begin{array}{l}\text { Saha et } \\
\text { al., } 2018 \\
\text { [9] }\end{array}$ \\
\hline 7 & P2 & $\begin{array}{l}\text { c. } 464 A>G \\
\text { p. }(\text { Asn155Ser })\end{array}$ & Childhood & $\begin{array}{l}\text { Proximal, upper } \\
\text { and lower } \\
\text { limbs, requires } \\
\text { cane since age } \\
54 \text {, facial } \\
\text { weakness }\end{array}$ & $\begin{array}{l}\text { Internal nuclei, } \\
\text { fiber size } \\
\text { variability }\end{array}$ & No & No & VC $40 \%$ & Ptosis, kyphosis & $\begin{array}{l}\text { Sainio et } \\
\text { al., } 2019 \\
{[10]}\end{array}$ \\
\hline \multirow[t]{2}{*}{8} & P3 & $\begin{array}{l}\text { c. } 464 A>G \\
\text { p.(Asn155Ser) }\end{array}$ & Adulthood & $\begin{array}{l}\text { Proximal and } \\
\text { axial, upper and } \\
\text { lower limbs, } \\
\text { requires cane } \\
\text { since age } 70\end{array}$ & NA & No & No & VC 67\% & - & $\begin{array}{l}\text { Sainio et } \\
\text { al., } 2019 \\
{[10]}\end{array}$ \\
\hline & P4 & & Adulthood & $\begin{array}{l}\text { Proximal and } \\
\text { axial, upper and } \\
\text { lower limbs, } \\
\text { wheelchair- } \\
\text { bound since } \\
\text { age } 66\end{array}$ & $\begin{array}{l}\text { Dystrophic } \\
\text { features, } \\
\text { myofibrillar } \\
\text { inclusions }\end{array}$ & No & No & VC $30 \%$ & - & \\
\hline
\end{tabular}


Table 1 Clinical, genetic, and histological features of patients with PYROXD1 mutations. All families have been numbered according to the mutation position. Homozygous mutations are highlighted in bold (Continued)

\begin{tabular}{|c|c|c|c|c|c|c|c|c|c|c|}
\hline Family & Patient & Mutation & Onset & $\begin{array}{l}\text { Muscle } \\
\text { weakness }\end{array}$ & $\begin{array}{l}\text { Muscle } \\
\text { histology }\end{array}$ & $\begin{array}{l}\text { Nasal } \\
\text { speech }\end{array}$ & Scoliosis & Respiration & Other features & Reference \\
\hline 9 & P1 & $\begin{array}{l}\text { c. } 464 A>G \\
\text { p.(Asn155Ser) } \\
\text { c.1061A > G } \\
\text { p.(Tyr354Cys) }\end{array}$ & Adulthood & $\begin{array}{l}\text { Proximal, upper } \\
\text { and lower limbs }\end{array}$ & $\begin{array}{l}\text { Internal nuclei, } \\
\text { fiber size } \\
\text { variability }\end{array}$ & No & No & VC 54\% & - & $\begin{array}{l}\text { Sainio et } \\
\text { al., } 2019 \\
{[10]}\end{array}$ \\
\hline 10 & E.II.2 & $\begin{array}{l}\text { c. } 464 A>G \\
\text { p.(Asn155Ser) } \\
\text { c.1159- } \\
1160 \text { insCAAA }\end{array}$ & Childhood & $\begin{array}{l}\text { Proximal, distal, } \\
\text { upper and } \\
\text { lower limbs, } \\
\text { facial weakness }\end{array}$ & $\begin{array}{l}\text { Internal nuclei, } \\
\text { cores }\end{array}$ & Yes & No & Normal & High-arched palate & $\begin{array}{l}\text { O'Grady } \\
\text { et al., } \\
2016[6]\end{array}$ \\
\hline \multirow[t]{2}{*}{11} & A.II.1 & $\begin{array}{l}\text { c. } 285+1 G>A \\
\text { c. } 1116 \mathrm{G}>\mathrm{C}_{1} \\
\text { p.Gln } 372 \mathrm{His}\end{array}$ & Childhood & $\begin{array}{l}\text { Proximal, distal, } \\
\text { axial, upper and } \\
\text { lower limbs, } \\
\text { facial weakness }\end{array}$ & $\begin{array}{l}\text { Internal nuclei, } \\
\text { cores, } \\
\text { myofibrillar } \\
\text { inclusions, } \\
\text { sarcomeric } \\
\text { disorganization, } \\
\text { rods }\end{array}$ & Yes & Yes & Abnormal & $\begin{array}{l}\text { Joint hypermobility, } \\
\text { contractures, rigid } \\
\text { spine, pectus } \\
\text { excavatum, high-arched } \\
\text { palate, dental malocclu- } \\
\text { sion, pes cavus }\end{array}$ & $\begin{array}{l}\text { O'Grady } \\
\text { et al., } \\
2016[6]\end{array}$ \\
\hline & A.II.2 & & Childhood & $\begin{array}{l}\text { Proximal, distal, } \\
\text { axial, upper and } \\
\text { lower limbs, } \\
\text { facial weakness }\end{array}$ & NA & Yes & No & Normal & $\begin{array}{l}\text { Joint hypermobility, } \\
\text { rigid spine, high-arched } \\
\text { palate, dental } \\
\text { malocclusion }\end{array}$ & \\
\hline 12 & P3 & $\begin{array}{l}\text { c. } 415-976 \mathrm{~A}>\mathrm{G} \\
\text { c. } 1116 \mathrm{G}>\mathrm{C}, \\
\text { p.GIn372His }\end{array}$ & Neonatal & $\begin{array}{l}\text { Proximal, distal, } \\
\text { axial, upper and } \\
\text { lower limbs, } \\
\text { wheelchair- } \\
\text { bound since } \\
\text { age } 13\end{array}$ & $\begin{array}{l}\text { Internal nuclei, } \\
\text { cores, } \\
\text { myofibrillar } \\
\text { inclusions, rods }\end{array}$ & Yes & Yes & $\begin{array}{l}\text { NIV since } \\
\text { age } 15\end{array}$ & $\begin{array}{l}\text { High-arched feet, hand } \\
\text { length asymmetry, low- } \\
\text { set ears, decreased } \\
\text { bone density }\end{array}$ & $\begin{array}{l}\text { This } \\
\text { study }\end{array}$ \\
\hline
\end{tabular}

NIV non-invasive ventilation, VC vital capacity

neonatal hypotonia and delayed motor milestones, and a progressive axial, proximal, and distal muscle weakness requiring a wheelchair since the age of 13. Respiratory insufficiency necessitates non-invasive ventilation since the age of 15 , and nasal speech, low-set ears, high-arched feet, hand length asymmetry (Fig. 1), mild septal and decreased anteroseptal dyskinesia, and reduced bone density were also diagnosed.

Whole body MRI was performed for P1 and P3 and revealed a similar picture with generalized and symmetric atrophy and diffuse fatty infiltrations with particular involvement of proximal lower limb muscles such as gluteus maximus, vastus lateralis, vastus intermedius, and vastus medius.

\section{Muscle sections show common findings of multiple internalized nuclei and cores}

Histological and histochemical analyses on muscle sections from all three patients described in this study revealed fiber size variability, endomysial fibrosis, and
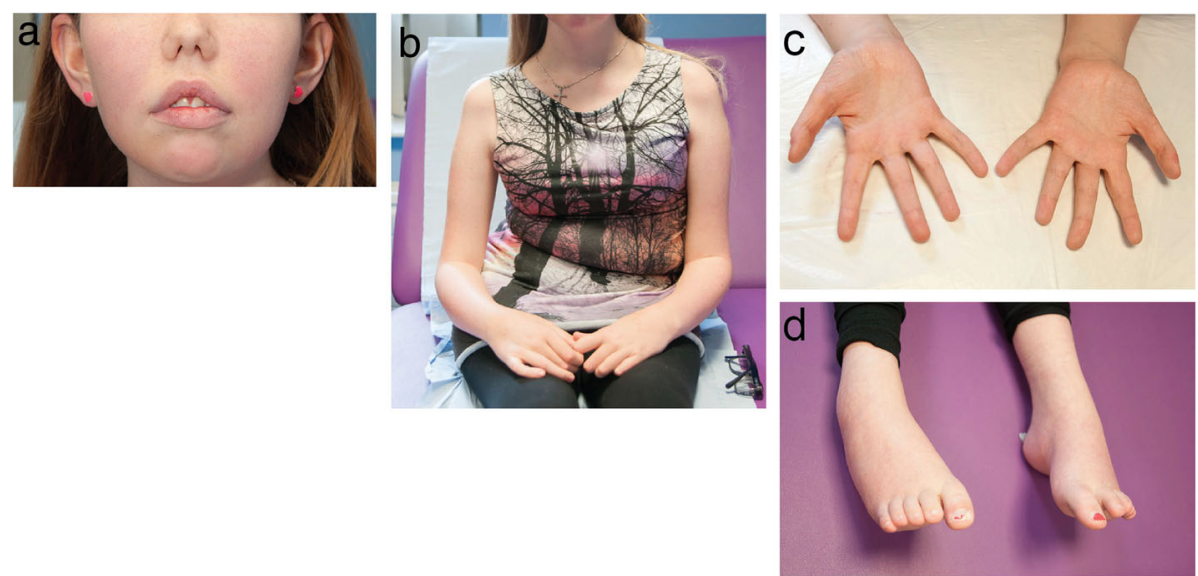

Fig. 1 Photographs of P3. a Low-set ears, b scoliosis, c hand size asymmetry, $\mathbf{d}$ arched feet 
especially grouped fibers with multiple internalized nuclei and numerous cores (Fig. 2). Fuchsinophilic inclusions consistent with cytoplasmic rods were furthermore observed on the biopsy from P2 and P3. Ultrastructural investigations on muscle biopsies from P2 and P3 confirmed the presence of cores, rods, and internal nuclei, and uncovered extensive myofibrillar disorganization (Fig. 3). In addition, osmiophilic membranous structures of unknown origin were seen adjacent to the sarcolemma and within fibers in P3.

To further characterize the structural aberrations in the muscle fibers, we performed a series of immunolabeling experiments on muscle sections from P2 and P3. We found abnormal aggregations of the intermediate filament desmin, the myofibrillar protein myotilin, and the chaperone alpha-crystallin B (Fig. 4), all three mutated in myofibrillar myopathies. We furthermore detected a subset of fibers expressing foetal myosin, and we noted marked accumulations of the autophagosome marker p62. We also found fibers with dark focal areas strongly staining positive for $\mathrm{COX}$, and areas with reduced COX staining, potentially corresponding to cores. Overall, the clinical, histological, and ultrastructural features of our patients were strongly suggestive of PYROXD1-related myopathy.

\section{Identification of PYROXD1 mutations}

We performed panel sequencing of 210 neuromuscular disorder genes for P1 (Family 1), and detected compound heterozygous PYROXD1 mutations. Segregation analysis disclosed the c. $285+1 \mathrm{G}>\mathrm{A}$ mutation affecting the essential donor splice site of the in-frame exon 3 on the paternal allele, and the common PYROXD1 c.464A > G (p.(Asn155Ser)) missense mutation on the maternal allele (Fig. 5). The younger brother was found to carry the same compound heterozygous PYROXD1 mutations, confirming recessive disease inheritance. Exome sequencing of P2 revealed the common c.464A > G (p.(Asn155Ser)) missense mutation at the homozygous state, and direct Sanger sequencing of PYROXD1 in P3 identified the heterozygous c.1116G > C (p.Gln372His) mutation, which was previously reported in an unrelated family [6]. Since the clinical and histopathological features of P3 were strongly indicative of PYROXD1-related myopathy, we extracted the skeletal muscle RNA, performed quantitative RT-PCR, and analyzed the reverse transcribed PYROXD1 coding sequence. We found a strong reduction of the PYROXD1 mRNA level compared with an age-matched control, and we detected the c.1116G > C (p.Gln372His) mutation at the homozygous state on the cDNA, demonstrating that expression of the

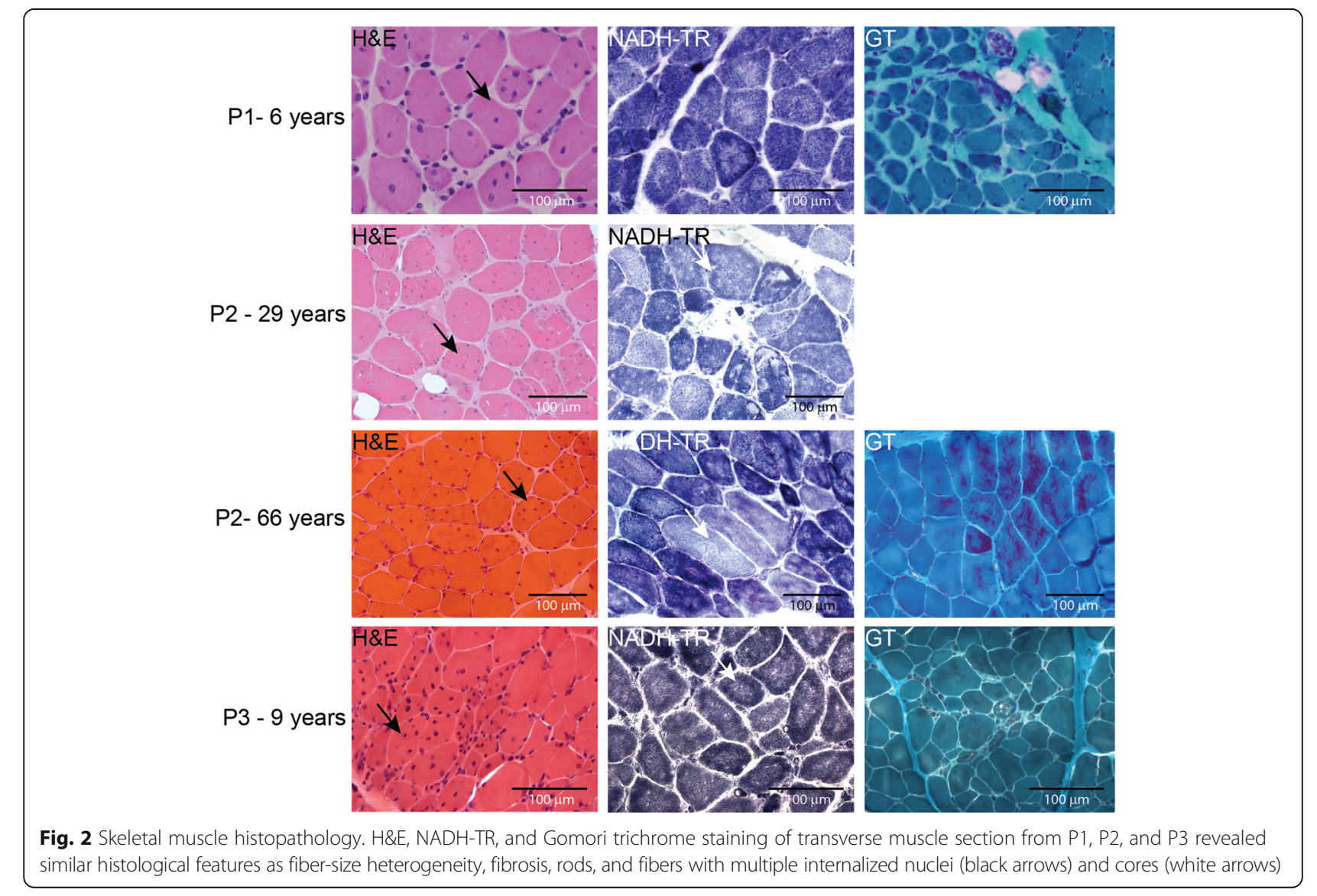




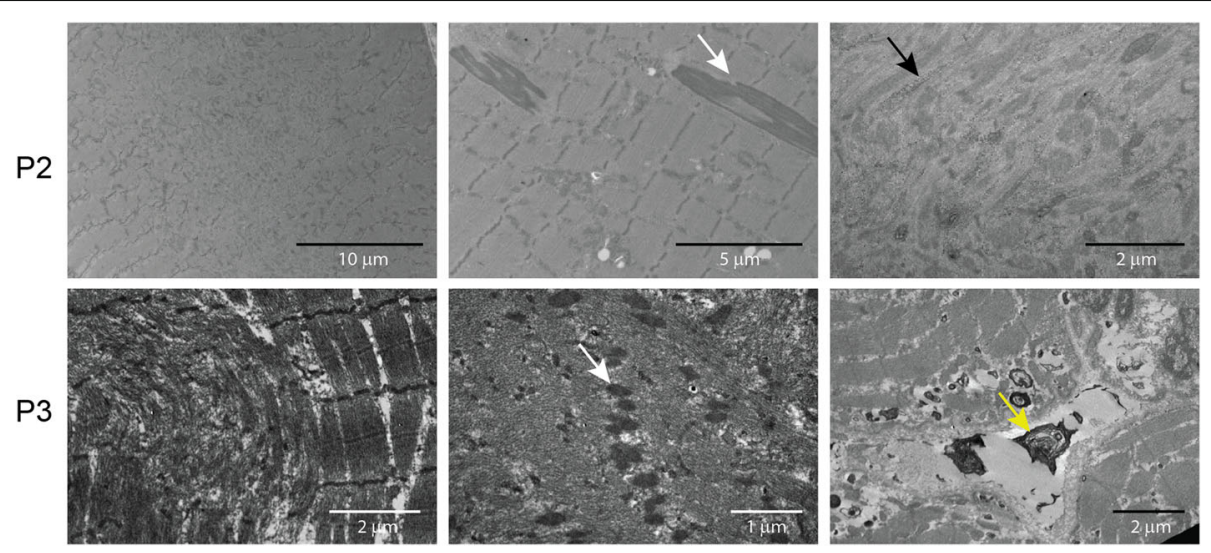

Fig. 3 Skeletal muscle ultrastructure. Electron microscopy on muscle section from P2 and P3 confirmed the presence of cores and rods (white arrows), and revealed glycogen accumulations (black arrow), abnormal mitochondria, and dense osmiophilic bodies (yellow arrow) of unknown origin outside the sarcolemma and within fibres

second allele was strongly attenuated (Fig. 6). To specifically amplify and enrich the second allele containing the wild-type guanine at cDNA position 1116, we performed PCR using a discriminative primer, and subsequent electrophoresis revealed the presence of a band with increased size (Fig. 6). Extraction and sequencing of the aberrant amplicon uncovered an insertion of 110 nucleotides containing an in-frame stop codon between exons 4 and 5. We next Sanger-sequenced the entire intron 4 on genomic DNA from P3 and detected the deep intronic c.415-976A > G mutation. This transition is not listed in the public databases, and in-silico analyses through NNSplice, MaxEntScan, and SpliceSiteFinderlike predict that it significantly enhances the recognition of a cryptic GT donor splice at positions c.415-979 and c.415-980. Taken together, the c.415-976A > G mutation activates an intronic cryptic slice site and induces the exonisation of 110 nucleotides between exons 4 and 5 . The presence of an in-frame stop codon within the cryptic exon presumably leads to nonsense-mediated mRNA decay (NMD) of the aberrant transcript. It has indeed been shown that NMD is efficiently triggered if the stop codon is at least 50-55 nucleotides upstream of the last exon-exon junction [4].

\section{Increased levels of the stress markers HSP70 and glutathione reductase}

PYROXD1 is a ubiquitously expressed protein containing an oxidoreductase domain, and functional investigations in yeast and mammalian cell models provided the evidence of a reductase activity that can antagonize the effects of oxidative stress [6,9]. To further investigate the impact of the identified PYROXD1 mutations on muscle physiology, we assessed the expression levels of
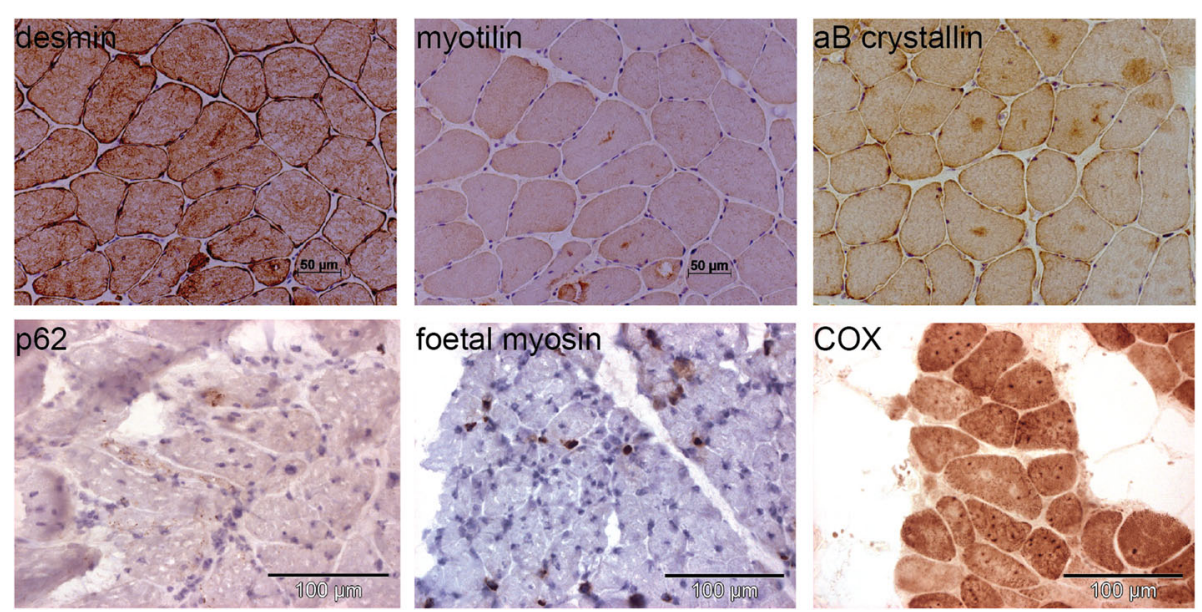

Fig. 4 Protein accumulations in patient muscles. Immuno- and chemical staining of muscle biopsies from P2 and P3 revealed accumulations of the myofibrillar proteins desmin, myotilin, and alpha B crystallin, and of the mitochondrial marker COX, and detected a few fibers expressing foetal myosin, or with positive labelling for the p62 autophagy marker 
a

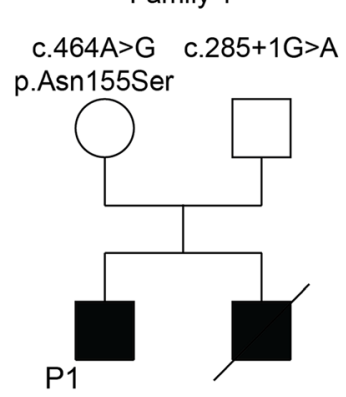

Heterozygous C. $1116 \mathrm{G}>\mathrm{C}$

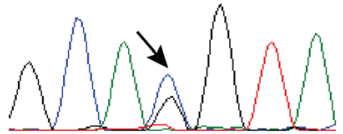

Heterozygous C.415-976A>G

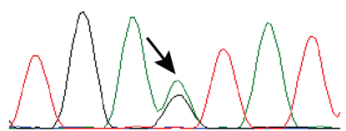

Family 2

c. $464 A>G \quad$ c. $464 A>G$ p.Asn155Ser p.Asn155Ser

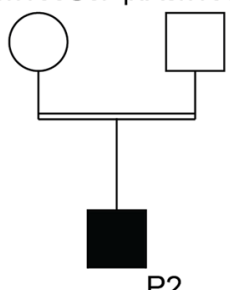

Homozygous c.464A>G

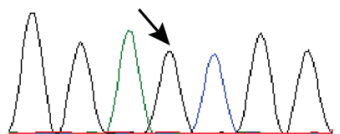

$b$

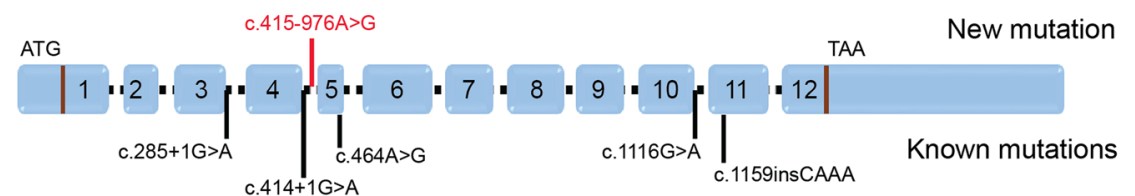

Family 3

c. $1116 \mathrm{G}>\mathrm{C} \quad$ c. $415-976 \mathrm{~A}>\mathrm{G}$ p.GIn372His

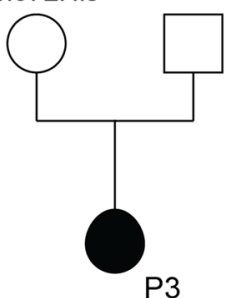

Heterozygous c.464A>G

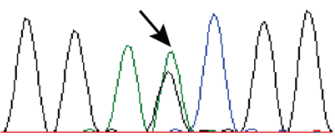

Heterozygous c. $285+1 \mathrm{G}>\mathrm{A}$

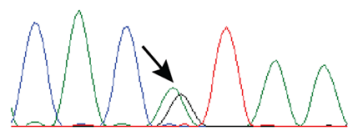

Fig. $\mathbf{5}$ Identification of PYROXD1 mutations. a Pedigrees of three novel PYROXD1 families and chromatopherograms showing the mutations. b Schematic representation of PYROXD1 and position of known mutations (black) and the novel mutation (red)

a

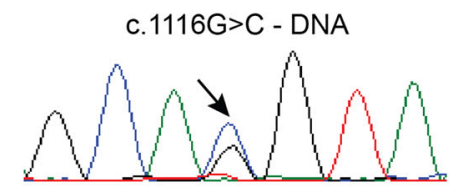

b

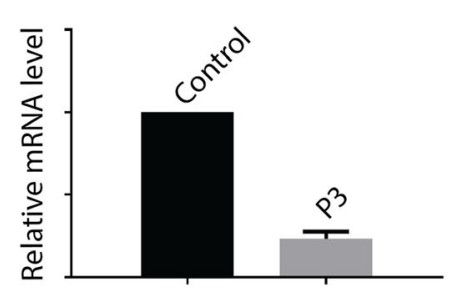

c. $1116 G>C$ - RNA

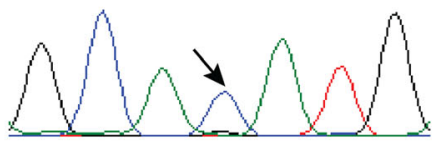

C

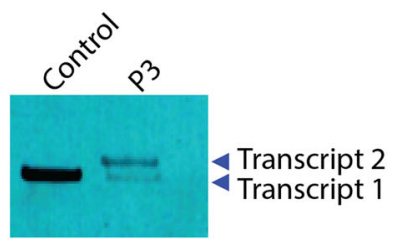

d

Transcript 2

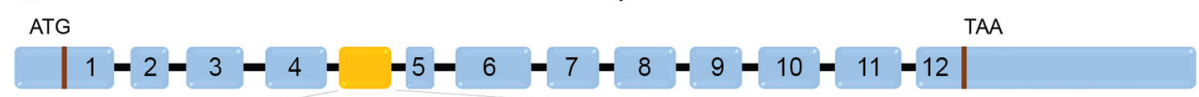

tcacctctag GTCCAGTGCTCTTGCAGATGTTTCTTAAATTGCAATATCCTCAATGAAGGACAAACTGAAATAAACTTCAGTTGTTTTTTTCTTGGAGAATTTTAAAGATGTCAGCTTCAgtgaggtatta

Fig. 6 Characterization of the deep intronic mutation. a The c.1116G > C mutation appears heterozygous on the P3 DNA and homozygous on the RNA. $\mathbf{b}$ The PYROXD1 mRNA was strongly reduced in the muscle from P3. c Discriminative PCR on skeletal muscle cDNA revealed the presence of an aberrant amplicon with increased size (transcript 2). d Sequencing of the aberrant transcript 2 showed the inclusion of an additional $110 \mathrm{nt}$ exon with in-frame stop codon (highlighted in black). The intronic mutation (red) reinforces a cryptic donor site (green) 
HSP70 and glutathione reductase in muscle extracts from P2 and a previously reported PYROXD1 patient with the common p.(Asn155Ser) missense mutation (B.II.2) [6]. HSP70 is a heat shock protein and glutathione reductase is implicated in oxidoreduction, and both are known to be upregulated in skeletal muscle in response to cellular stress $[3,11]$. Western blot revealed increased HSP70 and glutathione reductase signal intensities in P2 and B.II.2 compared to age-matched controls, and quantification showed that both proteins are significantly more abundant in the patient muscles (Fig. 7). This suggests that the PYROXD1 mutations result in increased oxidative stress, which presumably contributes to the skeletal muscle pathology of the patients.

\section{Discussion}

Here we describe three new families with recessive PYROXD1 mutations, and we support our findings by clinical, histological, ultrastructural, and genetic data. All patients presented with early-onset and progressive myopathy, and the biopsies revealed myofibrillar inclusions and multiple internal nuclei and cores as common features. The abundance of HSP70 and glutathione reductase in the patient muscles suggests that oxidative stress contributes to the pathology.

\section{Genotype/phenotype correlation}

Exome, panel, or Sanger sequencing identified recessive missense or intronic PYROXD1 mutations in the three patients described in this study. The c.464A > G (p.(Asn155Ser)) missense mutation was found at the compound heterozygous state in P1 and at the homozygous state in P2, and has previously been reported in eight PYROXD1 families from different ethnic origin [6, $9,10]$. The public gnomAD database lists 12 heterozygous and no homozygous carriers of the PYROXD1 c.464A > G mutation among almost 140,000 individuals. For other PYROXD1 mutations as c. $285+1 \mathrm{G}>\mathrm{A}$, p.(Tyr354Cys), and p.Gln372His, gnomAD respectively lists 22, 4, and 5 heterozygous carriers and not a single homozygous carrier, and this low frequency in the general population is in agreement with the rare occurrence of recessive PYROXD1 mutations associated with a human disorder.

Including our patients, a total of 12 PYROXD1 families have been described to date, and all had a progressive course of disease with a predominant involvement of upper and lower limb muscles. As a general rule, carriers of homozygous (p.(Asn155Ser)) or compound heterozygous missense mutations (p.(Asn155Ser) and p.(Tyr354Cys)) appear to exhibit a LGMD-like phenotype with childhood or adulthood disease onset and only little additional clinical
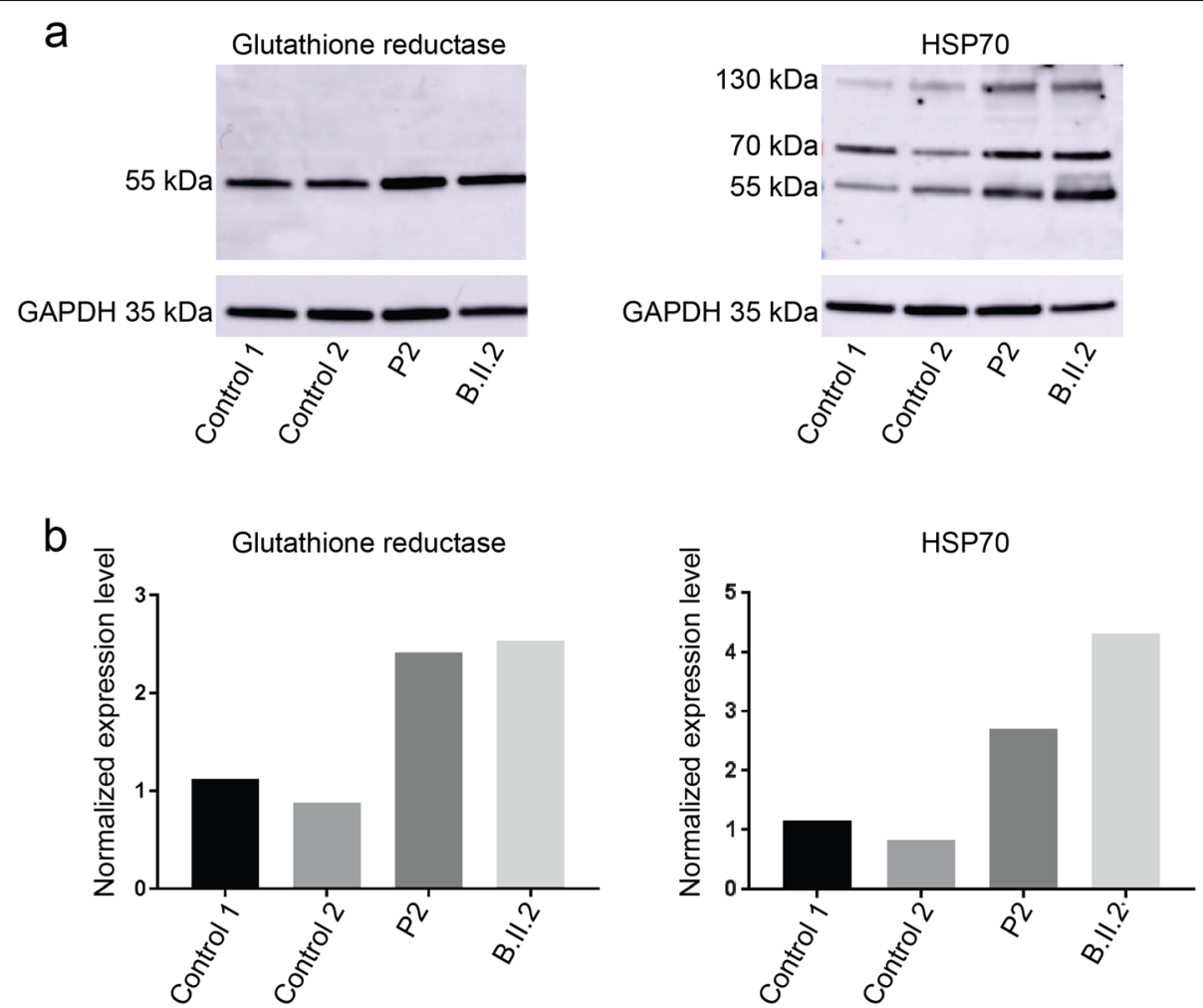

Fig. 7 Increased oxidative stress markers. a Western blot and $\mathbf{b}$ quantification on muscle extracts from two PYROXD1 patients revealed increased protein levels of HSP70 monomers $(70 \mathrm{kDa})$ and dimers $(140 \mathrm{kDa})$ and glutathione reductase compared with age-matched controls 
features (this study and $[6,9,10])$. By contrast, patients with splice mutations (c. $285+1 G>A$; c. $414+1 G>A$; c.415976A $>$ G) are most often affected at birth or infancy, and manifest a more severe and complex clinical picture including scoliosis, nasal speech, joint hypermobility, contractures, rigid spine, pectus excavatum, and anomalies of the feet and hands (this study and [6]). It was shown that the mutations affecting the essential splice sites of the in-frame exons 3 and 4 interfere with the production of a stable PYROXD1 protein [6], and here we demonstrated that the deep intronic c.415-976A > G mutation found in P3 impaired transcript expression. This illustrates that all identified splice mutations involve a reduction of the overall PYROXD1 protein level, which manifestly contributes to the development of a more severe and early-onset phenotype. Noteworthy, the splice mutations were exclusively found at the heterozygous state and in combination with a heterozygous missense mutation, suggesting that homozygous splice mutations might be embryonically lethal or give rise to a severe systemic disorders not classified and recognized as myopathies.

\section{Multiple internal nuclei and cores as histopathological hallmarks}

The biopsies from the patients described in this study displayed similar histological features of fiber size variability, endomysial fibrosis, and the presence of characteristic groups of muscle fibers with multiple internalized nuclei and cores. Electron microscopy additionally revealed prominent myofibrillar disorganization and occasional rods, consistent with the histological and ultrastructural observations in previously reported PYR$O X D 1$ cases [6]. Internal and central nuclei, cores of varying size and rods define specific forms of congenital myopathies [8], but a considerable overlap with coexistence of histopathological abnormalities has been described as well [2]. The combination of multiple internal nuclei and cores within single fibers constitutes a typical histopathological indication of PYROXD1-related myopathy.

As previously shown [6] and confirmed in the present study, the muscle fibers from PYROXD1 patients also featured myofiber disorganization and accumulations of myofibrillar proteins as desmin, myotilin, or alpha B crystallin. Although primarily seen in myofibrillar myopathy, the accumulations were also described in different forms of core myopathy $[1,12]$. Vacuoles, another hallmark of myofibrillar myopathy, have not been detected in any PYROXD1 biopsy. Overall and in view of the histological characteristics on biopsies as cores, central nuclei, and sarcoplasmic aggregates, PYROXD1-related myopathy can be considered as mixture of core myopathy, centronuclear myopathy, and myofibrillar myopathy. This highlights the relevance of PYROXD1 sequencing in patients with different histopathological diagnosis.

\section{Impact of PYROXD1 mutations on muscle physiology}

We investigated the structural muscle fiber aberrations in our patients by additional immunolabeling experiments, and detected foetal myosin and found evidences of enhanced autophagy. PYROXD1 is an oxidoreductase, and complementation assays in the yeast have shown that the missense mutations p.(Asn155Ser) and p.(Gln372His) strongly impair the oxidoreductase activity, and thereby increase the sensitivity of the cells to oxidative stress [6]. Oxidative stress can cause mitochondrial damage and impair mitochondrial function, and was also shown to promote the formation of cores in muscle fibers [7]. As PYROXD1 deficiency was furthermore associated with reduced mitochondrial respiration in cultured myoblasts [9], we may speculate that the aberrant skeletal muscle function and structure in PYR$O X D 1$ patients is partially a consequence of increased oxidative stress. This is supported by our findings of increased expression of HSP70 and glutathione reductase in the patients.

\section{Conclusions}

Nine families with recessive PYROXD1 mutations have been reported to date, and here we present clinical, histological, and genetic data on three novel families. We expand the genetic spectrum of PYROXD1-related myopathy and report for the first time a deep intronic mutation. By comparing all new and published cases, we furthermore provide a genotype/phenotype correlation. PYROXD1 codes for a barely studied oxidoreductase and should be considered in patients with early-onset muscle weakness predominantly affecting the limbs, especially if the muscle biopsy shows multiple internal nuclei and cores within individual fibers.

\section{Acknowledgements \\ We thank the families for their interest and participation to the study, and we thank Nicolas Dondaine for technical assistance.}

\section{Authors' contributions}

$N B R$, JL designed the study, NBR, JL, and JB coordinated the study. $X L, V S, I B$, $B L, V B$ performed the experiments. TW, AEL, SS, RQ, MF, CS, NBR contributed clinical samples, histological and patient data. $\mathrm{XL}$, JB wrote the manuscript. All authors read and approved the final manuscript.

\section{Funding}

This work was supported by Inserm, CNRS, University of Strasbourg, Labex INRT (ANR-10-LABX-0030, ANR-10-IDEX-0002-02), France Génomique (ANR10-INBS-09) and Fondation Maladies Rares within the frame of the "Myocapture" sequencing project, Association Française contre les Myopathies (AFM16992, AFM-17088, AFM-21267), and CREGEMES.

Availability of data and materials

All data generated or analyzed during this study are included in this published article. 


\section{Ethics approval and consent to participate}

Molecular diagnosis was carried out with written informed consent from the patients or legal guardians. DNA storage and usage was IRB-approved (DC2012-1693).

\section{Consent for publication}

All authors agree with the content of the manuscript, and all patients or legal guardians consented to the publication.

\section{Competing interests}

The authors declare that they have no competing interests.

\section{Author details}

${ }^{1}$ Institut de Génétique et de Biologie Moléculaire et Cellulaire (IGBMC), 1 rue Laurent Fries, 67404 Illkirch, France. ${ }^{2}$ Inserm U1258, Illkirch, France. ${ }^{3} \mathrm{CNRS}$ UMR7104, Illkirch, France. ${ }^{4}$ Strasbourg University, Illkirch, France. ${ }^{5}$ Laboratoire de Diagnostic Génétique, Faculté de Médecine, CHRU, Strasbourg, France. ${ }^{6}$ Wolfson Centre of Inherited Neuromuscular Disorders, RJAH Orthopaedic Hospital, Oswestry, UK. Department of Neurology, APHP, CHU de Bicêtre, Le Kremlin Bicêtre, France. ${ }^{8}$ French National Reference Center for Rare Neuropathies (NNERF), Le Kremlin Bicêtre, France. ${ }^{9}$ Inserm U1195 \& Paris-Sud University, Le Kremlin Bicêtre, France. ${ }^{10}$ Laboratoire de Génétique Médicale, Strasbourg University, Strasbourg, France. ${ }^{11}$ MRC Centre for Neuromuscular Diseases, National Hospital for Neurology and Neurosurgery, London, UK. ${ }^{12}$ Université Sorbonne, UPMC Paris 06 University, Inserm UMRS974, CNRS FRE3617, Center for Research in Myology, GH Pitié-Salpêtrière, Paris, France. ${ }^{13}$ Centre de Référence de Pathologie Neuromusculaire Paris-Est, Institut de Myologie, GHU Pitié-Salpêtrière, Assistance Publique-Hôpitaux de Paris, Paris, France. ${ }^{14}$ Neuromuscular Morphology Unit, Myology Institute, GHU Pitié-Salpêtrière, Paris, France. ${ }^{15}$ Service Neurologie Médicale, Centre de Référence Maladies Neuromusculaire Paris-Nord, CHU Raymond-Poincaré, Garches, U1179 UVSQ-INSERM Handicap Neuromusculaire: Physiologie, Biothérapie et Pharmacologie appliquées, UFR des sciences de la santé Simone Veil, Université Versailles-Saint-Quentin-en-Yvelines, Montigny-le-Bretonneux, France. ${ }^{16}$ Department of Pathology, Strasbourg University Hospital, Strasbourg, France. ${ }^{17}$ Dubowitz Neuromuscular Centre, UCL Institute for Child Health and Great Ormond Street Hospital, London, UK.

Received: 20 June 2019 Accepted: 25 July 2019

Published online: 27 August 2019

\section{References}

1. Dubowitz V, Sewry CA, Oldfors A (2013) Muscle biopsy; a practical approach 4th edn. Elsevier, Oxford

2. Gonorazky HD, Bonnemann CG, Dowling JJ (2018) The genetics of congenital myopathies. Handb Clin Neurol 148:549-564. https://doi.org/10.1 016/B978-0-444-64076-5.00036-3

3. Ji LL, Fu R (1992) Responses of glutathione system and antioxidant enzymes to exhaustive exercise and hydroperoxide. J Appl Physiol (1985) 72:549-554. https://doi.org/10.1152/jappl.1992.72.2.549

4. Maquat LE (2004) Nonsense-mediated mRNA decay: splicing, translation and mRNP dynamics. Nat Rev Mol Cell Biol 5:89-99. https://doi.org/10.1038/ nrm1310

5. Nance JR, Dowling JJ, Gibbs EM, Bonnemann CG (2012) Congenital myopathies: an update. Curr Neurol Neurosci Rep 12:165-174. https://doi. org/10.1007/s11910-012-0255-x

6. O'Grady GL, Best HA, Sztal TE, Schartner V, Sanjuan-Vazquez M, Donkervoort S, Abath Neto O, Sutton RB, Ilkovski B, Romero NB et al (2016) Variants in the oxidoreductase PYROXD1 cause early-onset myopathy with internalized nuclei and Myofibrillar disorganization. Am J Hum Genet 99:1086-1105. https://doi.org/10.1016/j.ajhg.2016.09.005

7. Paolini C, Quarta M, Wei-LaPierre L, Michelucci A, Nori A, Reggiani C, Dirksen RT, Protasi F (2015) Oxidative stress, mitochondrial damage, and cores in muscle from calsequestrin-1 knockout mice. Skelet Muscle 5:10. https://doi. org/10.1186/s13395-015-0035-9

8. Romero NB, Clarke NF (2013) Congenital myopathies. Handb Clin Neurol 113:1321-1336. https://doi.org/10.1016/B978-0-444-59565-2.00004-6 B978-0444-59565-2.00004-6

9. Saha M, Reddy HM, Salih MA, Estrella E, Jones MD, Mitsuhashi S, Cho KA, Suzuki-Hatano S, Rizzo SA, Hamad MH et al (2018) Impact of PYROXD1 deficiency on cellular respiration and correlations with genetic analyses of limb-girdle muscular dystrophy in Saudi Arabia and Sudan. Physiol Genomics 50:929-939. https://doi.org/10.1152/physiolgenomics.00036.2018

10. Sainio MT, Valipakka S, Rinaldi B, Lapatto H, Paetau A, Ojanen S, Brilhante V, Jokela M, Huovinen S, Auranen M et al (2019) Recessive PYROXD1 mutations cause adult-onset limb-girdle-type muscular dystrophy. J Neurol 266:353-360. https://doi.org/10.1007/s00415-018-9137-8

11. Salo DC, Donovan CM, Davies KJ (1991) HSP70 and other possible heat shock or oxidative stress proteins are induced in skeletal muscle, heart, and liver during exercise. Free Radic Biol Med 11:239-246

12. Selcen D, Shen XM, Brengman J, Li Y, Stans AA, Wieben E, Engel AG (2014) DPAGT1 myasthenia and myopathy: genetic, phenotypic, and expression studies. Neurology 82:1822-1830. https://doi.org/10.1212/WNL. 0000000000000435

\section{Publisher's Note}

Springer Nature remains neutral with regard to jurisdictional claims in published maps and institutional affiliations.
Ready to submit your research? Choose BMC and benefit from:

- fast, convenient online submission

- thorough peer review by experienced researchers in your field

- rapid publication on acceptance

- support for research data, including large and complex data types

- gold Open Access which fosters wider collaboration and increased citations

- maximum visibility for your research: over $100 \mathrm{M}$ website views per year

At $\mathrm{BMC}$, research is always in progress.

Learn more biomedcentral.com/submissions 